\title{
EN TORNO AL TRATAMIENTO LEXICOGRÁFICO DE LA FRASEOLOGÍA HUMORÍSTICA*
}

\author{
ON THE LEXICOGRAPHICAL APPROACH TO THE \\ HUMOROUS PHRASEOLOGY
}

\author{
LARISSA TIMOFEEVA \\ Universidad de Alicante. Alicante, España \\ timofeeva@ua.es
}

\section{RESUMEN}

Este trabajo centra su atención en la representación lexicográfica de la fraseología humorística. El humor, aun siendo un fenómeno eminentemente pragmático, forma parte del significado de algunas unidades fraseológicas (UF). Sin embargo, son confusos los criterios para considerar un fraseologismo como humorístico, lo cual provoca la disparidad de descripciones lexicográficas recogidas en distintos diccionarios. Por eso, tras un análisis de la significación fraseológica y de los puntos básicos del humor lingüístico, intentamos aunar ambos enfoques con el fin de elaborar pautas claras de determinación del carácter humorístico de algunas UF y, por ende, de la inclusión de la marca correspondiente en sus descripciones lexicográficas.

Palabras clave: Fraseología, humor, lexicografía.

\begin{abstract}
This article focuses on the lexicographical representation of the humorous phraseology. Humor, even being a mainly pragmatic phenomenon, is part of the meaning of certain phraseological units. However, the criteria to consider an idiom as humorous are vague,

"Este trabajo se inserta en el marco del Proyecto de Investigación FFI2012-30941 "Innovaciones lingüísticas del humor: Géneros textuales, identidad y enseñanza del español”, financiado por el Ministerio de Economía y Competitividad de España. Asimismo, es resultado de las investigaciones llevadas a cabo por los grupos GRIALE (http://www.griale.es/) y ACQUA (http://www.ua.es/grupo/acqua/) de los que formamos parte. En este sentido, quisiéramos agradecer especialmente a las doctoras Ruiz Gurillo y Santamaría Pérez el acceso que nos han facilitado a sus trabajos todavía en prensa. Asimismo, damos las gracias a la doctora Ruiz Gurillo por sus comentarios sobre la primera versión de este artículo.
\end{abstract}


what favours the disparity of lexicographical descriptions present in different dictionaries. Therefore, we analyse the phraseological meaning and the basic points of the linguistic humor in an attempt to bring together both approaches. We aim, thus, to develop clear criteria for determining the humorous nature of some phraseological units and, hence, for the corresponding lexicographical marking.

Keywords: Phraseology, humour, lexicography.

Recibido: 12.06.2012. Aceptado: 23.12.2012.

\section{INTRODUCCIÓN}

Zl estudio del humor constituye en la actualidad uno de los temas de mayor interés para muchas disciplinas, entre ellas la lingüística que está desarrollando su propio andamiaje teórico en relación a diversas manifestaciones del humor a través del lenguaje. Una de estas manifestaciones presenta un aliciente aun mayor, derivado de su especificidad, tanto semántica como pragmática. Nos referimos a las unidades fraseológicas (UF), concretamente, a aquellas que han codificado el humor como parte de su semántica.

Está fuera de cualquier debate que el humor lingüístico constituye un hecho pragmático, por lo que resulta inviable su estudio sin atender a los factores que se dan en un intercambio comunicativo y que presentan, por definición, una gran variedad determinada por las circunstancias del uso de una lengua. A primera vista, no parece posible abarcar y sistematizar todos estos factores, si bien es evidente que existen una serie de pautas comunicativas que guían el desarrollo de diversas consecuencias implicaturales, entre ellas el humor.

Las UF presentan, en este sentido, un valor especial, ya que aúnan una naturaleza enunciativa con un comportamiento sincrónico propio de un lexema. Todo ello alienta una indagación en las particularidades del funcionamiento de las UF, con el fin de optimizar su estudio lingüístico especialmente con fines aplicados. Por eso, el humor, como hecho pragmático que ha pasado a formar parte de la semántica fraseológica, representa un reto investigador. En este trabajo queremos asumir este reto y reflexionar sobre la representación lexicográfica de las UF humorísticas, con el objetivo de proponer criterios claros que pauten tal representación.

Como pretendemos poner de manifiesto, los criterios que guían la marcación de las UF como humorísticas en diversos diccionarios resultan sumamente vagos e inconsistentes. La raíz del problema se encuentra, a nuestro juicio, en la desatención hacia la dinámica del significado fraseológico, por un lado, y del humor, por el otro. La labor de encajar ambos fenómenos, que ha de realizar la lexicografía para adecuar sus descripciones, tiene que fundamentarse en criterios nítidos que sean aplicables al análisis de cualquier manifestación fraseológica humorística. Por 
eso queremos buscar las vías de desarrollo de tales criterios en este trabajo.

Para ello, organizaremos nuestra reflexión según sigue. En primer lugar, en el apartado 2 hablaremos sucintamente de problemas generales de la representación del significado fraseológico en los diccionarios. Examinaremos algunos defectos de los que adolece el tema para proponer, en el punto 3, una visión alternativa de la significación fraseológica que, en nuestra opinión, puede tener interesantes implicaciones fraseográficas. Lo intentaremos mostrar, en el apartado 4, en relación al tratamiento lexicográfico del humor y la fraseología con el fin de diseñar las pautas que, a nuestro modo de ver, deberían regir la imbricación lexicográfica de ambos fenómenos. A la luz de tal diseño analizaremos en el punto 5 algunas UF que, o bien aparecen sancionadas en diversas obras lexicográficas como humorísticas o bien deberían hacerlo si atendemos a su significado. En efecto, la aplicación de criterios propuestos revela que hay UF cuya sanción resulta cuanto menos dudosa; y que hay otras que cumplen los requisitos señalados y deberían, por tanto, ser marcadas como humorísticas en los diccionarios. En el apartado 6 recogemos unas breves conclusiones, así como algunas consideraciones de cara a las investigaciones futuras.

\section{LA FRASEOLOGÍA EN LOS DICCIONARIOS}

Como hemos apuntado, en este artículo abordaremos una pequeña parcela de una problemática mucho más amplia que se refiere al tratamiento lexicográfico del lenguaje fraseológico. Y es que, a pesar de la relativamente tardía incorporación de la lingüística española al estudio de la fraseología ${ }^{1}$, la representación lexicográfica de las unidades fraseológicas, o la fraseografía, pronto se convirtió en uno de los temas centrales de la nueva disciplina. Semejante interés resulta más que comprensible, ya que la fijación y la descripción de toda la complejidad de la significación fraseológica determina aspectos tales como su enseñanza y aprendizaje a los alumnos extranjeros o su traslación a otras lenguas.

En la actualidad, en el ámbito español contamos con una ciertamente amplia bibliografía dedicada a este tema (una revisión al respecto en Robles, 2007). No obstante, a nuestro juicio, la mayor parte de esta bibliografía adolece del mismo defecto, pues presenta una concepción bastante estática y "monofacética” del sig-

${ }^{1}$ Aunque el primer acercamiento serio al estudio lingüístico de la fraseología, el de J. Casares, data de 1950, fue, por diversos motivos, una oportunidad perdida, pues la fraseología española no despuntó hasta varias décadas más tarde. En los años 80 se publicaron en español varias obras de referencia, pero mayoritariamente provenientes de fuera de España (v. g. Zuluaga, 1980; Carneado y Tristá, 1983). Fue la década de los 90 del siglo pasado la que se convirtió en la Edad de Oro de la fraseología en España, ya que en esa época se publican las obras clave, como Corpas Pastor (1996), Martínez Marín (1996), Ruiz Gurillo (1997), que determinaron el desarrollo de la disciplina y su actual estado. 
nificado fraseológico, sin atender a toda la gama de valores, semánticos y pragmáticos que emergen como resultado del proceso de la fraseologización. Por ejemplo, en el grueso de los trabajos se sigue operando con las categorías meramente formales a la hora de describir la naturaleza locucional ${ }^{2}$, por lo que la información gramatical que clasifica las locuciones en nominales, verbales, adjetivales, etc., se acepta como criterio de partida y no se somete a ningún tipo de debate sobre su papel en la significación fraseológica ${ }^{3}$.

Y sin embargo, a nuestro modo de ver, hemos de partir de la función central, básica y natural de las UF, que consiste, al igual que de una palabra cualquiera, en designar objetos, acciones, sentimientos, relaciones, etc. Por tanto, debemos indagar en cómo denominan las UF, en por qué lo hacen y qué ventajas ofrece tal tipo de denominación respecto a la realizada por lexemas simples. La información gramatical, que, obviamente, también forma parte de dicha función denominativa, representa, no obstante, valores ciertamente periféricos que complementan, pero no determinan, el elenco de informaciones de diversa índole que encierra el significado de una UF.

La tradición fraseográfica basada en la prioridad del criterio gramatical puede generar, además, descripciones que se presten a confusión, especialmente para un hablante no nativo del español. Veamos algunos ejemplos:

\section{(1) Saltar a la vista}

El Diccionario de la lengua española (DRAE) o el Diccionario fraseológico documentado del español actual (DFDEA) marcan esta locución como verbal, esto es, cuyo significado nos remite a algún tipo de acción. No obstante, a continuación la define como "ser claro, evidente". A todas luces, más que una acción, la locución saltar a la vista denomina una cualidad, con lo cual funcionalmente se asemeja, si es tan preciso indicarlo, a un adjetivo. Al menos así parece funcionar

${ }^{2}$ Tal preponderancia del criterio formal constituye una valiosa, pero ya desfasada herencia de los primeros acercamientos a la fraseología desde la lingüística (Bally, 1951; Casares, 1950; Vinogradov, 1977) que, como bien se sabe, respondían a la metodología estructuralista de índole inductiva que evitaba introducir en sus consideraciones las vagas nociones como intención, situación, contexto social, etc. El estructuralismo partía de los datos empíricos en tanto que datos observables, pero su postura impedía avanzar hipótesis que pudieran explicar los mecanismos subyacentes al funcionamiento de los signos lingüísticos en el discurso (cfr. Meix, 1982: 21 y ss.; Alcaraz, 1990: 46 y ss.). Son aspectos que más tarde estarían en el punto de mira del cognitivismo y la pragmática.

${ }^{3}$ Lo vemos explícitamente en DFDEA (XVI), cuando define las locuciones como "agrupaciones más o menos fijas de palabras, conjuntos que tienen su función gramatical (nombre, pronombre, adjetivo, verbo, adverbio, preposición, etc.) como la tienen las palabras individuales; y que también, como si fuesen palabras individuales, tienen un valor estable propio que no es la suma de los de sus componentes" (cursiva en el original). 
en los enunciados como:

(2) Su belleza que salta a la vista no le permite, sin embargo, consolidar su carrera de modelo

(3) Tu error salta a la vista y es imperdonable

Veamos ahora otro ejemplo. La locución un ojo de la cara en el DFDEA es marcada como nominal con indicación de su género, en este caso, el masculino. Sin embargo, la acepción contiene una anotación sobre su frecuente combinatoria con los verbos como costar o cobrar, que para el DRAE, por ejemplo, forman parte de la locución, lo que le permite considerarla como verbal. Tal consideración contrasta, a nuestro juicio, con la definición que se ofrece de esta locución, esto es, "Ser excesivo su precio, o mucho el gasto que se ha tenido en ello" (DRAE). En otras palabras, significa "ser algo muy caro" ${ }^{4}$. Asimismo, combinando las perspectivas de ambos diccionarios, el DFDEA y el DRAE, todo parece indicar que se trata de una locución que se comporta funcionalmente como un adverbio, es decir, "costar / cobrar algo a alguien muy caro". Entonces, la pregunta que nos hacemos es ¿de qué nos sirve la información gramatical ofrecida en ambos casos? ¿Nos ayuda, realmente, a comprender los matices funcionales que tendrá la locución en tanto que elemento de discurso?

Junto con todo lo dicho, existe otro aspecto que revela, en nuestra opinión, cierta incoherencia. En los dos casos expuestos arriba es evidente que la determinación de la categoría gramatical de la locución se basa en el papel, o bien del elemento principal del sintagma o bien, directamente, del que lo encabeza 5 . Por eso, si el DFDEA establece en el segundo caso analizado los límites de la locución en un ojo de la cara la trata como nominal, mientras que si el DRAE incluye en la combinación también al verbo, la misma locución se convierte en verbal. Siguiendo el mismo criterio, el DFDEA considera, por ejemplo, que borrón y cuenta nueva con el significado de "decisión de olvidar deudas o faltas pasadas y de actuar en lo sucesivo como si no hubieran existido" es una locución nominal de género masculino (por el elemento borrón, se entiende). No obstante, tal categorización no responde a la definición de locución en los preliminares del Diccionario que mencionamos líneas más arriba. En dicha definición leemos que las locuciones son "conjuntos que tienen su función gramatical (nombre, pronombre, adjetivo,

${ }^{4}$ Cfr. DFEM: [costar/valer u. c.] un ojo de la cara a alguien (inf.) "[Costar/ valer] demasiado".

${ }^{5}$ Wotjak (1983: 68-69) ya señalaba que una clasificación que buscase establecer equivalencias entre las categorías gramaticales y las locuciones tendría en cuenta la categoría del componente básico de la locución. Sin embargo, como apuntaba el autor, pese a la estrecha vinculación entre la forma y la función, no las podemos confundir ni identificar. Así, una clasificación funcional debe fundamentarse en el establecimiento de paralelos entre la locución y el papel que ésta desempeña en el discurso, ya sea sintáctica, semántica o pragmáticamente hablando. 
verbo, adverbio, preposición, etc.)" (la negrita es nuestra). Y sin embargo, si volvemos a nuestro ejemplo, la consideración del conjunto borrón y cuenta nueva como un sustantivo de género masculino no ayuda a comprender en toda su profundidad su significado, máxime si comprobamos que su actuación como locución estrictamente hablando se produce en la mayoría de los casos acompañada de un verbo, sobre todo hacer; y que el uso "nominal" se da, principalmente, en lo que DFDEA clasifica como fórmulas oracionales (DFDEA: XVII), esto es, locuciones enunciativas $^{6}$ que, si bien comparten muchos aspectos con las locuciones, presentan una mayor autonomía oracional. ¿Es, entonces, hacer borrón y cuenta nueva una locución verbal cuyo significado, por tanto, habría que reformular en términos correspondientes, es decir, "decidir olvidar deudas o faltas pasadas y de actuar en lo sucesivo como si no hubieran existido"? ¿Qué información sobre el comportamiento discursivo de esta locución nos aporta una u otra consideración?

El examen de ejemplos como estos pone de manifiesto que el establecimiento de parámetros gramaticales como base de la descripción del significado de una UF no siempre nos lleva a buen puerto, por lo que habría que tener en cuenta otro tipo de informaciones que configuran la función denominativa de las UF. En el siguiente apartado vamos a considerar un modelo de significación fraseológica que pretende aunar todas estas informaciones como configuradoras de dicha función.

\section{EL SIGNIFICADO FRASEOLÓGICO: UN MODELO EXPLICATIVO}

En Timofeeva (2012) abogamos por la consideración del significado fraseológico en dos niveles de su actuación. Así, en el primer nivel se sitúa lo que tradicionalmente llamamos el significado convencionalizado de la expresión, el que aparece en el diccionario. En el segundo, se analiza qué consecuencias tienen las características de primer nivel a la hora de insertar la UF dentro de un enunciado mayor. En otras palabras, el primer nivel recogería los rasgos semánticos de la UF mientras que el segundo atendería al comportamiento pragmático y discursivo de la UF.

Siguiendo esta concepción bidimensional, en el primer nivel adoptamos el marco del modelo macrocomponencial propuesto por Telia $(1990,1996)$ que articula el significado de una UF en torno a una serie de bloques informativos, cada uno de los cuales explicita un parámetro explicativo de tal significado. Así, destacamos el bloque denotativo que indica el referente de la UF, por ejemplo, poner pies en polvorosa como "huir, escapar" (DRAE).

En segundo lugar, en el bloque motivacional, recogemos la información sobre

${ }^{6}$ Dobrovol'skij, en un trabajo de 1990 sobre la tipología de las expresiones idiomáticas, analiza las características de este tipo de construcciones y propone una serie de criterios que motivan su inclusión dentro de la clase de locuciones. Para más detalles remitimos al lector a Dobrovol'skij, 1990; Baranov y Dobrovol'skij, 2000; Dobrovol'skij y Piirainen, 2005, o Timofeeva, 2012: 153-155. 
la imagen que sostiene el significado de una UF, es decir, ese "puente" basado en operaciones cognitivas de diversa índole que media entre la composición lexemática de la UF y su significado actual. Así, por ejemplo, en unos casos, esa proyección motivacional parte de la lectura literal de la combinación y en otros, el proceso de establecimiento de vínculos cognitivos puede sugerirnos, simplemente, la primera situación comunicativa donde oímos y supimos inferir correctamente el significado de la locución. Cabe señalar que es el componente informativo central de cualquier UF, pues para un hablante siempre existe una vinculación motivacional que le impulsa a elegir una UF en vez de un lexema simple de denominación primaria (cfr. Feyaerts, 2006: 61-65). Aplicado al ejemplo anterior de poner pies en polvoro$s a$, la motivación que subyace a dicha locución nos puede sugerir una imagen de algo que al pasar rápidamente por un sitio levanta mucho polvo.

En el tercer bloque recogemos la información evaluativa racionalizada en términos cuantitativos (más de la norma - norma - menos de la norma) y cualitativos (positivo - indiferente - negativo). En nuestro caso, parece que la locución poner pies en polvorosa adquiere una evaluación cuantitativa en términos de mayor intensidad, mientras que cualitativamente parece mostrarse neutra.

En el cuarto bloque, el de evaluación emotivo-emocional, nos centramos en el sentimiento-actitud que pretendemos transmitir y causar en nuestro interlocutor al eligir una determinada UF, es decir, la fuerza ilocutiva y el buscado efecto perlocutivo de la locución. Esto está estrechamente relacionado con el bloque anterior, y en nuestro caso podemos afirmar que cuando un hablante elige poner pies en polvorosa pretende transmitir al oyente al menos la intensidad de la acción, lo que le ayudará a ponderar los efectos implicaturales adicionales que se generarán en el contexto comunicativo concreto (i. e. en el segundo nivel).

En el quinto bloque es la información estilística la que ocupa nuestra atención, es decir, el registro al que habitualmente se adscribe la locución, coloquial en nuestro caso, según el DRAE.

Y finalmente, y de un modo ciertamente periférico, en el sexto bloque localizamos la información gramatical, en la medida en que la adscripción de la locución a una determinada categoría gramatical tiene, obviamente, consecuencias semánticas ${ }^{7}$. En nuestro ejemplo tenemos una locución verbal que, efectivamente, nos remitirá a un referente accional ${ }^{8}$.

Estas informaciones sistematizadas en el modelo forman la semántica fraseológica $y$, por tanto, tienen que estar recogidas de alguna manera en una repre-

\footnotetext{
${ }^{7}$ Se trata de una de las principales reivindicaciones del cognitivismo, en cuya concepción un valor gramatical es semántico en esencia, por lo que las fronteras entre la forma y el contenido son sumamente borrosas (cfr. Cifuentes, 1994; Cifuentes, 2003; Cuenca y Hilferty, 1999; Dobrovol'skij y Piirainen, 2005; Levinson, 2004: 398 y sigs.).

${ }^{8}$ Remitimos al lector a Timofeeva (2012: cap. 6) para una explicación más detallada del contenido de los bloques informativos del modelo, así como de las relaciones que se establecen entre ellos.
} 
sentación lexicográfica. Hay que subrayar que dichas informaciones en realidad actúan como implicaturas con diverso grado de convencionalización, por lo que nos encontramos ante lo que Levinson (2004) denomina la intrusión pragmática en la semántica, y que subraya, una vez más, el carácter eminentemente pragmático del significado fraseológico.

Su complejidad, que emerge como resultado de un desarrollo contextual, se identifica, sin embargo, con el de un lexema simple en el segundo nivel de significación, donde, como hemos dicho, nos interesa el comportamiento discursivo de la UF. En este sentido, consideramos que el grado de convencionalización de las implicaturas de primer nivel tiene consecuencias en ese comportamiento en los siguientes términos: si estamos ante implicaturas muy convencionalizadas, éstas se mantienen en el nivel discursivo e incluso imponen su tónica a todo el enunciado. Sin embargo, las informaciones inferidas del significado fraseológico de primer nivel que responden a las características de las implicaturas generalizadas pueden verse alteradas o canceladas al insertarse la UF dentro de un enunciado mayor (cfr. Timofeeva, 2012: 245-253).

El modelo de significación fraseológica sucintamente presentado pone de manifiesto, a nuestro juicio, la necesidad de replantear la presentación de fraseologismos en los diccionarios, pues, como hemos podido advertir a través de los ejemplos citados arriba, una parcela importante de información configuradora del significado de una UF, o bien se queda fuera del diccionario o bien se presenta de manera confusa. Obviamente, una obra lexicográfica, al menos la tradicional, es decir, en papel, no puede incluir explícitamente el desglose de informaciones por bloques, pero sí se habría de cambiar el enfoque y convertir la función, y no la forma, en el punto de partida de la descripción lexicográfica ${ }^{9}$. Por otra parte, la situación parece distinta si pensamos en obras lexicográficas electrónicas, pues las herramientas informáticas sí permiten, e incluso prefieren, la representación desglosada del significado de una UF. De hecho, el modelo macrocomponencial de Telia $(1990,1996)$ que tomamos como referencia para nuestra propuesta, se planteó inicialmente para un proyecto de un fondo electrónico de unidades fraseológicas que se desdibujó ciertamente por las circunstancias históricas del momento en que se concibió.

A partir de las premisas desarrolladas abordaremos en el siguiente apartado el estudio de las UF que aluden en su semántica al valor humorístico. Concretamente, analizaremos algunas locuciones que se recogen en diferentes obras lexicográficas con la marca de humorístico, así como aquellas otras que, a nuestro juicio,

${ }^{9}$ En esta línea, Wotjak, en el ya citado trabajo (1983: 68), afirmaba que "no basta completar la clasificación formal con la descripción semántica. Hace falta caracterizar las UF de acuerdo con las funciones que desempeñan en la comunicación, en el habla; habrá que clasificarlas según su función comunicativa, teniendo en cuenta que se trata de unidades léxicas consistentes de forma y contenido". 
son susceptibles de considerarse y, por tanto, ser marcadas como tales. Nuestro objetivo, recordemos, consiste en diseñar unos criterios operativamente útiles para el tratamiento lexicográfico de la marca "humorístico" para la fraseología.

\section{LAS UF Y EL HUMOR}

Si echamos un vistazo a los distintos tipos de obras lexicográficas nos daremos cuenta de que la fraseología humorística ocupa en ellos un lugar nada menospreciable. En efecto, podemos comprobar que son muchas las locuciones que recogen los diccionarios tanto fraseológicos como generales que llevan esta marca que indica "la actitud del hablante" (DFDEA), "la valoración general de los hablantes ante las realidades designadas, o matices expresivos no deducibles de la escueta definición” (DUE), "información de naturaleza sociolingüística y estilística” (Alcalá: $\mathrm{XIV)} \mathrm{o} \mathrm{"las} \mathrm{posibilidades} \mathrm{de} \mathrm{uso} \mathrm{en} \mathrm{ciertas} \mathrm{circunstancias} \mathrm{de} \mathrm{algunas} \mathrm{expresiones} \mathrm{y}$ términos" (Salamanca: XI), por poner algunos ejemplos. Como vemos, estas anotaciones tienen que ver más con el comportamiento pragmático de las unidades lingüísticas, el que se despliega al insertarlas dentro de un contexto, determinado por condiciones ilocutivas concretas. Tal circunstancia da lugar, como también señala Santamaría (2011), a cierta paradoja, pues estamos hablando de codificar en el diccionario una característica de uso y, por consiguiente, circunstancial por definición. Es obvio, por tanto, que en la mayoría de los casos la sanción humorístico no irá más allá de orientaciones y recomendaciones ciertamente generales que guíen al usuario acerca del posible efecto perlocutivo de esta índole.

Si bien esta última afirmación es evidente, en el caso de las UF la cuestión se torna más compleja. Como analizábamos en un trabajo anterior sobre la expresión de la ironía a través de las UF (Timofeeva, 2009a), una de las consecuencias claras de la fraseologización de una combinación libre es que ciertos valores inferenciales se regularizan al entrar en una cadena gramaticalizadora en la que las implicaturas particularizadas iniciales se van convencionalizando hasta llegar a formar parte de la semántica de la UF ${ }^{10}$. En este sentido, afirmábamos que la ironía en tanto que característica semántica, puede presentar distintos grados de convencionalización, lo cual nos permitía hablar de las UF semánticamente irónicas prototípicas y periféricas, cuyo comportamiento discursivo (i. e. el segundo nivel) estaría marcado por el grado de la convencionalización del valor irónico.

A nuestro juicio, la misma explicación puede ser aplicada a la codificación del humor $^{11}$ en la fraseología, por lo que sí resulta pertinente considerar la presencia

${ }^{10}$ Esto es un claro ejemplo de la intrusión de la pragmática en la semántica de Levinson (2004) que señalamos líneas más arriba.

${ }^{11} \mathrm{E}$ incluso, en mayor grado, puesto que, como afirma Attardo (2001b), mientras que la ironía es un fenómeno puramente pragmático, el humor tiene claramente dos facetas, la semántica y la 
de la marca pragmática del humor en la descripción lexicográfica de las UF. Ahora bien, a la tarea de delimitar qué es el humor ${ }^{12}$ se suma, en este caso, la de determinación de los criterios que sirvan para considerar una UF como semánticamente humorística y, por tanto, susceptible de ser marcada como tal en el diccionario.

A nuestro modo de ver, el modelo de la significación fraseológica que resumimos arriba puede contribuir a aclarar esta cuestión, ya que provee bases explícitas en las que se sustentan las diversas informaciones que configuran la complejidad semántica de las UF. Siguiendo esta reflexión, la hipótesis que nos planteamos es que la "búsqueda" del humor semántico ha de partir del análisis del primer nivel del significado fraseológico, esto es, de las informaciones sistematizadas en el modelo macrocomponencial ${ }^{13}$ que presentamos arriba. De esta forma, si en este análisis encontramos indicios que nos lleven a una interpretación humorística en alguno o en varios de los componentes del modelo, tendremos un criterio lo suficientemente claro para sancionar una UF con la marca correspondiente.

Una vez establecida esta hipótesis, nos queda, como hemos advertido, otro problema, el de determinar qué es un indicio humorístico, o dicho de otro modo, qué nos hará interpretar algo como humorístico. Naturalmente, la decisión cae aquí dentro de una problemática mucho más amplia, que ha sido objeto de muchos trabajos y que, además, todavía no tiene una respuesta única ${ }^{14}$.

Para los fines de este trabajo, y sin ánimo de entrar en complejos debates sobre el tema, asumiremos una visión ampliamente compartida por la mayoría de los estudiosos del fenómeno del humor lingüístico ${ }^{15}$, que consiste en contemplarlo

pragmática. Si bien es cierto que en Timofeeva (2009a) intentamos demostrar que las UF pueden contradecir la afirmación de Attardo y codificar el valor irónico como parte de su semántica, no nos cabe duda de que las posibilidades semánticas del humor son aun mayores debido a su carácter más genérico. Como señala Attardo (2001b: 166): "Lexicographic studies have shown that the semantic field of what has been broadly defined as 'humor' is very rich in closely related, barely distinguishables terms", por lo que un gran número de matices del significado podrá acogerse bajo la etiqueta de humorístico.

${ }^{12}$ Tarea que, en primer lugar, ha de distinguir entre el humor como fenómeno psicológico y el humor lingüístico. Este último ha sido enfocado desde diversas teorías lingüísticas y semióticas, como resumía Attardo (1994: 332-334). De manera más reciente, Ruiz Gurillo (2012) señala que en la actualidad el estudio del humor lingüístico se plasma en tres acercamientos principales: desde la Lingüística Cognitiva, la Teoría de la Relevancia y la Teoría General del Humor Verbal (TGHV), esta última postulada expresamente para el estudio de este fenómeno.

${ }^{13}$ Aunque resulte obvio, debemos recordar que la presentación del significado fraseológico de primer nivel como un conjunto de bloques informativos tiene fines puramente metodológicos y no responde a la realidad, ya que en ésta todas las informaciones se activan simultáneamente y establecen una estrecha red de relaciones e influencias. Para más detalle sobre estas cuestiones se puede consultar Timofeeva (2012: cap. 6).

${ }^{14}$ En palabras de Attardo (1994: 3): "The problems for an essentialist theory of humor are manifold, and the definitional issue [...] is far from straightforward".

${ }^{15}$ Para Attardo (1994: 332), las teorías lingüísticas del humor se limitan al humor expresado a través de los signos, lo cual les proporciona mayor claridad metodológica frente a los modelos psicológicos. 
en el marco del modelo psicológico de incongruencia-resolución ${ }^{16}$. Dicho modelo, cuyas líneas básicas fueron desarrolladas en Suls (1972), afirma la existencia de dos etapas en el proceso de interpretación del humor ${ }^{17}$. En la primera de ellas, el oyente, que crea una serie de expectativas sobre el posible desenlace a raíz de los datos recopilados en el procesamiento de la información, se encuentra con que es víctima de engaño, ya que sus expectativas resultan incongruentes con el desenlace real. De esta forma, pasa a una segunda etapa, en la que intenta encontrar interpretaciones alternativas de la situación con el fin de resolver la incongruencia. Si el oyente da con esa regla cognitiva que le permite ajustar el desenlace real al guión (script) planteado se deshace la incongruencia y se produce efecto humorístico. En este sentido, y pese a que ello sigue siendo objeto de debate, parece que la sola existencia de la incongruencia no es suficiente para que se produzca el humor, ya que la segunda etapa de resolución es la que proporciona al oyente esa sensación de fruición cognitiva al descubrir el engaño. Por otra parte, puesto que el hablante que actúa con la intención humorística está interesado en que el oyente descubra el valor ilocutivo de su enunciado, puede proporcionarle una serie de pistas hacia una resolución correcta de la incongruencia.

Esta explicación, aunque convenientemente simplificada, del humor lingüístico nos lleva a desarrollar la siguiente reflexión en lo que a su aplicación a la fraseología humorística se refiere. En primer lugar, hemos asumido que la semántica de las UF (i. e. primer nivel) está configurada por un conjunto de informaciones sistematizadas a través de un modelo macrocomponencial. En segundo lugar, hemos considerado que son dos las fases obligatorias (incongruencia y resolución) que llevan a una interpretación humorística de un enunciado. Por tanto, para que una UF sea codificada como humorística, ha de recoger en su primer nivel del significado ambas etapas conducentes al humor y, además, puede contener alguna pista fijada en su semántica que guíe hacia tal efecto perlocutivo.

Con todo lo dicho, es importante subrayar que el humor fraseológico presentará ciertas particularidades que derivan del carácter convencionalizado del significado de las UF. A diferencia del humor "libre", el fraseológico constituye, como hemos comentado arriba, una implicatura con alto grado de convencionalización, por lo que se aprende por el hablante como parte del significado global y no se genera ni se actualiza en el discurso como una implicatura conversacional particularizada. Por ello, las fases de incongruencia y resolución no se darán de manera equivalente a las expresiones libres y tan solo podemos detectar rastros de aquellos estadios dia-

${ }^{16}$ Una amplia bibliografía confirma esta afirmación, donde encontramos las obras ya clásicas como Raskin (1985), Attardo (1994, 2001a), Latta (1998), Norrick (1993), Ross (1998) y en el ámbito español contamos con las aportaciones de Torres Sánchez (1999) o Ruiz Gurillo (2012), entre otros.

${ }^{17}$ Naturalmente, hablamos aquí del humor intencionado, si bien es cierto que los efectos humorísticos no siempre son resultados intencionados (cfr. Raskin, 1985). 
crónicos en los que la expresión aún libre generó la implicatura humorística como resolución a una situación de incongruencia. No obstante, esta puntualización no invalida la hipótesis planteada, ya que la detección de los rasgos constituyentes del humor dentro del modelo presentado sigue siendo un criterio válido.

De esta manera, siguiendo el modelo del significado fraseológico de primer nivel descrito, cabe pensar que la fase de incongruencia se plasme especialmente en la relación entre el referente de la UF (i. e. el bloque denotativo) y el resto de los bloques informativos. En este sentido, la información contenida en el bloque denotativo remitirá al significado real mientras que el resto de informaciones aglutinarán expectativas creadas por el oyente y frustradas más tarde por las informaciones del referente. Con ello, la información denotativa configurará, asimismo, la fase de resolución, puesto que si el oyente desconoce o no se ve capaz de inferir correctamente el referente de la UF, su reacción puede ser de sorpresa o desconcierto aun cuando detecte la incongruencia, pero el proceso quedará inconcluso a falta de la otra fase. Por otra parte, el humor en tanto que factor resolutivo, deberá estar siempre presente en el bloque de evaluación emotivo-emocional, puesto que es parte del sentimiento-actitud que el hablante pretende transmitir a su oyente.

Además de lo dicho, creemos que la semántica humorística de una UF también puede presentar indicios de incongruencia "secundarios" que reforzarán los básicos y actuarán como pistas hacia una resolución humorística. Tales indicios pueden detectarse en el interior de distintos bloques del modelo de significación fraseológica de primer nivel, aunque el motivacional se presenta como el más susceptible de albergarlos.

A partir de estas reflexiones, a continuación nos planteamos un análisis de una serie de locuciones distintamente marcadas en los diccionarios consultados con el fin de corroborar nuestras hipótesis.

\section{LA FRASEOLOGÍA HUMORÍSTICA: ANÁLISIS DE EJEMPLOS}

En este apartado ofreceremos un sucinto análisis de UF concretas que permitirán comprobar las ideas planteadas arriba. Algunas de las locuciones estudiadas están sancionadas como humorísticas en diversas fuentes lexicográficas consultadas; otras, sin embrago, no llevan tal marcación, si bien su lectura sugiere esta posibilidad. Los diccionarios consultados para este análisis son el DFDEA, el DRAE, el DUE, así como el DFEM, Doval (1995) y Penadés Martínez (2002, 2005, 2008).

\subsection{Para el arrastre}

La primera UF que analizaremos es para el arrastre, locución adverbial con el sig- 
nificado de "en situación lamentable o penosa" (DFDEA) y verbal incluyendo el verbo estar y con el significado de "hallarse en extremo decaimiento físico o moral" (DRAE) o "estar inútil o incapaz de trabajar o de moverse, por cansancio, vejez, etc." (DUE). De entre todas estas definiciones, el DUE considera, además, que el hablante, al eligir estar para el arrastre se refiere a la realidad designada en términos humorísticos.

Si desglosamos el significado de esta locución de acuerdo con el modelo macrocomponencial presentado, con el objetivo de "localizar" el humor que codifica el DUE, vemos que en el bloque denotativo hablamos de una situación o un estado físico o moral de cansancio, decaimiento, etc., por lo que la fase de resolución obligatoria para una interpretación humorística, en principio, no contiene indicios de comicidad.

Respecto a la información motivacional, parece que la locución proviene del mundo taurino donde hace referencia a la parte final de la lidia cuando el toro muerto es retirado de la plaza. Sin embargo, no todos los hablantes conocen la etimología taurina, por lo que para muchos la imagen se sustenta en el significado del verbo arrastrar "llevar a alguien o algo por el suelo, tirando de él o de ello" (DRAE), y presenta una clara base metafórica orientacional de tipo Arriba / Abajo (v. g. FELIZ ES ARRIBA, TRISTE ES ABAJO; SALUD Y VIDA SON ARRIBA, LA ENFERMEDAD Y MUERTE SON ABAJO; TENER CONTROL O FUERZA ES ARRIBA; ESTAR SUJETO A CONTROL O FUERZA ES ABAJO; etc.). Tal base metafórica es perfectamente coherente con la información contenida en el bloque denotativo, por lo que nada nos indica la presencia de algún tipo de incongruencia imprescindible para considerar esta UF como humorística. Es cierto que existe una valoración hiperbólica, que podría verse como una posible pista hacia la interpretación humorística, pero la hipérbole, aun siendo muy frecuente su asociación con el humor, no lo desencadena automáticamente.

Si analizamos el bloque de evaluación racionalizada de [estar] para el arrastre, en nuestra opinión, la locución se caracteriza en el eje cuantificador como "más de la norma", pues indica un grado extremo de cansancio o agotamiento, matiz, por cierto, adecuadamente recogido en la definición del DRAE. En lo que se refiere al eje cualificador, podríamos pensar que la locución tiende ciertamente hacia el polo negativo, ya que no es bueno estar tan decaído; pero es posible que las circunstancias contextuales cancelen esta negatividad ${ }^{18}$. Como vemos, tampoco aquí detectamos rasgos de incongruencia.

Podemos pensar que en el siguiente bloque, el de evaluación emotivo-emocional, encontraremos las claves de la actitud humorística que, según el DUE, marca

${ }^{18}$ Dicho de otro modo, el valor indicado responde a su caracterización en términos de implicatura conversacional generalizada que, como demuestra Levinson (2004), resulta pieza clave para comprender el proceso de la gramaticalización de una unidad lingüística. 
la locución [estar] para el arrastre, ya que aquí se recogen los aspectos relativos a la fuerza ilocutiva de la locución. ¿Cuál es el sentimiento-actitud que intentamos transmitir a través de esta locución? ¿Qué efectos perlocutivos esperamos conseguir en nuestro interlocutor? Si analizamos los ejemplos concretos donde aparece la locución [estar] para el arrastre, parece que básicamente queremos ponderar el grado de penosidad de la situación y que nuestro interlocutor se haga partícipe de ella y experimente cierta solidaridad o compasión hacia la persona o cosa afectada. Esto sucede en (4) y (5):

(4) [...] tengo mucho sueño. [...] Y si no duermo ahora, mañana estaré para el arrastre (CREA: Arrabal, F. 1979. El cementerio de automóviles. Madrid. Cátedra).

(5) Amy Winehouse está para el arrastre. Disponible en http://soyplastic. net/2008/11/amy-winehouse-esta-para-el-arrastre/.

Comprobamos que, tanto en (4) como en (5), al usar [estar] para el arrastre el hablante pretende subrayar el grado extremo de cansancio, en primer caso, o de mal estado físico, en el segundo, con el fin de que su oyente comprenda y comparta tal extremidad y experimente sentimientos adecuados a ello. Una reacción humorística no parece contemplarse en estos casos o, al menos, no derivada de la semántica de la UF. Veamos ahora el ejemplo (6):

(6) No sé para qué le servirá la Unión Europea a Alemania o a Francia pongo por caso; para lo que sirve a sus demás miembros podría ser una buena definición de la nada. Que se lo pregunten a Grecia, por ejemplo, con la cuestión del islote que ellos llaman Imia y los turcos Kardak: la UE ha dado la callada por respuesta y ha mirado, silbando, hacia otra parte. O que nos lo pregunten a nosotros con respecto a los belgas (que no es verdad que sean franceses con un cuerno sólo): han suspendido la extradición de dos miembros del comando Vizcaya de ETA, y se han quedado tan panchos. Si a eso se llama unión, que a mí me den conflictos. Y si la unión hace la fuerza, pronto estaremos para el arrastre (CREA: GALA, A. 1996. "La unión”, El Mundo, 07/02/1996.

Este ejemplo es especialmente interesante, puesto que aquí [estar] para el arrastre parece adquirir un valor irónico. Sin embargo, dicho valor no viene dado por la actitud irónica codificada en el primer nivel del significado de la UF sino por el contexto, donde el entorno irónico se crea desde las primeras líneas ${ }^{19}$. Por ello, la

${ }^{19}$ Estaríamos, por tanto, ante lo que se define como una ironía continuada, es decir, "aquella que no aparece necesariamente en un enunciado concreto, sino a lo largo de todo un texto. No siempre presenta indicadores lingüísticos específicos, pero viene favorecida por un entorno irónico que, según Utsumi (2000: 1783-1784), consiste en la expectativa del hablante, en la incongruencia entre la 
ironía aparece aquí como una implicatura conversacional particularizada, esto es, totalmente condicionada por las circunstancias situacionales concretas.

De esta manera, llegamos al quinto bloque informativo de nuestro modelo, donde se recoge la información estilística. Los diccionarios consultados marcan [estar] para el arrastre como perteneciente al registro informal o coloquial, y la composición léxica de la locución (estar, arrastre) no difiere de esta adscripción. Esto nos indica que tampoco existe una disonancia estilística en esta UF que nos podría llevar hacia una interpretación en clave de humor.

Finalmente, el último bloque, el de datos gramaticales, en función del diccionario le adjudica a la locución, o bien un valor adverbial o bien verbal, lo que tampoco nos da ninguna pista sobre el carácter humorístico de su significado.

En definitiva, tras aplicar el modelo macrocomponencial que articula el significado fraseológico de primer nivel no hemos encontrado ningún indicio de incongruencia cuya resolución pueda llevarnos hacia una interpretación humorística, y por tanto, no vemos motivo alguno para dotar a la locución [estar] para el arrastre de un carácter humorístico. Obviamente, la implicatura humorística puede desencadenarse en el nivel discursivo (segundo nivel), pero su generación estará determinada por el contexto en el que aparece la locución, como hemos visto en el ejemplo (6), donde adquiere un matiz irónico.

\subsection{Servir lo mismo para un barrido que para un fregado}

La siguiente locución que queremos analizar es servir lo mismo para un barrido que para un fregado, que en el DFDEA es definida como "ser útil para todo", en el DUE “servir una persona para cualquier trabajo" o en el DRAE ${ }^{20}$ "Ser materia dispuesta para todo, o para cosas contrarias, como lo sagrado y lo profano, lo serio y lo jocoso, etc.”. Aunque se observe cierta disparidad de significado, grosso modo podemos decir que se trata de la utilidad de algo o alguien para muchas cosas y muy diversas. Este sería el bloque denotativo de esta locución que se opondría a la base imaginativa de la UF y concentraría la fase de resolución de una posible interpretación humorística.

En lo que se refiere al bloque motivacional, nos topamos con un fenómeno discursivo muy interesante, el de pseudoabarcación ${ }^{21}$. En efecto, la imagen de la

expectativa y la realidad y en una actitud negativa del hablante hacia su congruencia" (Ruiz Gurillo, Marimón, Padilla y Timofeeva, 2004: 237).

${ }^{20}$ En el Diccionario académico esta locución aparece como ser, o servir, lo mismo para un fregado que para un barrido.

${ }^{21}$ Baranov y Dobrovol'skij (1996) contemplan este fenómeno en relación al proceso de reinterpretación que sustenta la idiomatización de una expresión, y explican que se trata de enumerar algunos elementos formantes de un total que no lo agotan, pero que se reinterpretan como si lo hicieran (cfr. también Timofeeva, 2012: 136-137). 
locución se basa en la consideración de las acciones de barrer y de fregar como abarcadoras de un todo. Dicho de otro modo, se enumeran sólo dos acciones que forman parte del marco cognitivo "limpieza", de tal manera que sean reinterpretadas como si abarcaran no sólo el marco completo, sino la totalidad de acciones posibles. Encontramos este mismo fenómeno en otras locuciones, como no ser ni carne ni pescado, no ser ni chicha ni limonada, ni rey ni roque, no quitar ni poner rey, por fas o por nefas, no tener arte ni parte, no tener ni oficio ni beneficio, prometer el oro y el moro, tirios y troyanos, etc.

La pseudoabarcación produce frecuentemente un efecto humorístico por el mero hecho de englobar un todo a través de unos elementos en cuya elección influyen más factores de rima o parecido fónico que la representatividad del concepto en sí. De esta forma, se crea el necesario efecto de sorpresa que desencadena la incongruencia entre los datos del marco cognitivo fijado en la UF y el referente real $^{22}$. Asimismo, la pseudoabarcación cumple, en este caso, la función de pista hacia una resolución adecuada de la incongruencia en términos humorísticos.

La imagen que sostiene la locución servir lo mismo para un barrido que para un fregado produce en el bloque de evaluación emotivo-emocional un sentimiento de ponderación de la diversidad y la disparidad de las acciones y usos para los que está capacitado alguien o sirve algo. El hecho de querer abarcar todas las posibilidades con dos acciones tan cotidianas como barrer o fregar produce el efecto cómico que caracteriza a esta locución, pues es evidente que este "todo" también incluirá actos o propiedades sin ninguna relación con el marco de "limpieza".

En lo que se refiere a otros bloques informativos del modelo, no parecen aportar datos útiles relacionados con una interpretación humorística de esta locución, por lo que omitimos su análisis. Sólo cabe concluir que el desglose del significado de primer nivel de servir lo mismo para un barrido que para un fregado revela que resulta pertinente sancionarla como humorística en su tratamiento lexicográfico.

\subsection{Curva de la felicidad}

La siguiente locución que estudiaremos, curva de la felicidad, lleva la marca de humorístico en el DUE y en el DFDEA y se define como "barriga abultada. Se usa particularmente referido a las personas que por cambiar de estado, por ejemplo por haber contraído matrimonio, se abandonan y empiezan a engordar" (DUE) o "estómago abultado, frec. en los hombres de edad madura" (DFDEA). También el DFEM recoge una acepción similar: "barriga incipiente [se refiere siempre a

${ }^{22}$ Adviértase que si utilizáramos esta UF dentro del marco cognitivo "limpieza" y con un referente al que fueran aplicables las acciones fijadas (i. e. barrer y fregar), procederíamos seguramente a la lectura literal de los componentes de la locución, por lo que no habría ningún tipo de incongruencia. 
personas en edad madura]".

En este caso, la información denotativa establece una evidente relación de incongruencia con el componente de imagen que, literalmente, se relaciona con algo positivo (por el componente felicidad), mientras que el referente real nos remite a un estado de cierto abandono físico que conlleva consecuencias negativas, no solo estéticas sino también para la salud del individuo.

También observamos rasgos de incoherencia entre el bloque denotativo y el de evaluación racionalizada, ya que la posesión de esa curva de la felicidad se suele asociar a una vida tranquila y apacible, por lo que se espera que la valoración se establezca en términos positivos. Sin embargo, el marco denotativo resuelve semejante modo de vida como ciertamente negativo a causa de las consecuencias físicas que acabamos de mencionar. Una resolución humorística, por tanto, permite conjugar dos marcos muy distintos como el de la felicidad y el de declive físico; por lo que la locución curva de la felicidad cumple los criterios que hemos establecido para considerar una UF como semánticamente humorística y ha de marcarse como tal en el diccionario.

\subsection{Ciencia infusa, agua milagrosa, vida y milagros}

El siguiente caso que queremos analizar acoge, en realidad, varias locuciones cuya imagen se relaciona con hechos o fenómenos irreales e imaginarios. Concretamente, vamos a tratar las UF ciencia infusa, agua milagrosa y vida y milagros.

La primera de ellas, ciencia infusa, se define como "saber no adquirido mediante el estudio" y marcado como irónico en el DRAE o "se aplica a lo que alguien sabe o cree saber sin haberlo aprendido o estudiado" con marca de humorístico en el DUE. Con estos datos podemos afirmar que en el bloque denotativo de esta UF el referente se establece en términos de un saber poco riguroso. La incongruencia que nos lleva a la lectura humorística radica aquí en el componente de imagen, esto es, en el bloque motivacional de la locución. En efecto, ciencia, por definición, supone un tipo de formación y estudio previos, basados en observación y razonamiento estructurados y sistematizados; mientras que infuso se refiere a los dones que vienen directamente del cielo, pues son los que Dios infunde en las almas. Por tanto, la incongruencia se genera en la imagen y se resuelve en el bloque denotativo al referirse a ese conocimiento ciertamente inexacto.

Algo parecido sucede en agua milagrosa, definida en el DFDEA como "líquido con que el masajista trata a los jugadores lesionados" y con la marca de humorístico. Aquí, al igual que en el caso anterior, en el bloque motivacional encontramos señales de incongruencia, basadas en la imagen de una sustancia que, como aprendemos desde pequeños, es incolora, inodora e insípida y, sin embargo, posee aquí propiedades "que excede[n] a las fuerzas y facultades de la naturaleza" (DRAE). 
La resolución en clave humorística que se concentra en el bloque denotativo se refiere, por tanto, a la atribución de características impropias al líquido en cuestión.

Un caso aparte representa la UF vida y milagros, con el significado de "noticia detallada sobre las actividades pasadas y presentes [de una pers.]" (DFDEA), "Información completa sobre la vida, historia y conducta de una persona" (DUE) o "modo de vivir, mañas y travesuras de alguien, y en general sus hechos" (DRAE). En ninguno de los diccionarios citados la locución aparece marcada como humorística. Sin embargo, si desglosamos su significado según nuestro modelo, encontramos una serie de rasgos que sugieren la conveniencia de incluir tal marca en su descripción lexicográfica. En efecto, según vemos, en el bloque denotativo se establece como referente la trayectoria vital de una persona cualquiera. No obstante, si analizamos la información contenida en el bloque motivacional de esta UF, nos encontramos con que el concepto de "milagro" forma parte de la vida de personajes legendarios o míticos, como los santos, pero no de personas normales. De esta forma, es evidente el rastro de una situación de incongruencia que nos lleva a una resolución humorística, o incluso irónica o burlesca, del significado de esta UF. Adviértase que en la definición que propone el DRAE todo hace pensar en tal caracterización.

Esta última UF nos conduce, asimismo, a otra reflexión que resulta pertinente y extensible también a las otras dos. Y es que si nos fijamos en el bloque estilístico, observaremos que en las tres locuciones se da cierta incongruencia también a ese nivel. En efecto, las tres UF nos remiten a un marco muy concreto de supersticiones y creencias religiosas, y los elementos infusa, milagrosa y milagros se adecuan a la situación comunicativa original. Sin embargo, el hecho de sacar del contexto a los referentes de las expresiones originales produce el efecto de mezcla de registros que desencadena el humor. Podríamos decir que se da, en cierto modo, la desautomatización discursiva ${ }^{23}$ de las combinaciones iniciales que sí hacían referencia a personas y hechos extraordinarios, lo cual genera la comicidad e, incluso, la burla. Por ello, la marca correspondiente ha de formar parte de la descripción lexicográfica de estas UF.

\subsection{Abogado de secano}

La falta de criterios claros para sancionar una UF como humorística provoca casos confusos como el de la locución abogado de secano, que en el DFDEA está registrada con la marca despectivo, y definida como "abogado que no ejerce o que tiene poca competencia profesional. Frec. fig, referido a quien alardea de perito en leyes,

${ }^{23}$ Este tipo de desautomatización fraseológica se refiere a un uso inadecuado de la UF desde el punto de vista del discurso (cfr. Timofeeva, 2009a, Timofeeva, 2009b). 
sin serlo". Esta última acepción figurada es la que centra nuestra atención.

Por su parte, el DRAE recoge cuatro acepciones manifiestamente susceptibles de considerarse humorísticas, entre las que sólo una está marcada como burla: “1. [...] Jurista que no ejerce ni sirve para ello. 2. [...] El que sin haber cursado la jurisprudencia entiende de leyes o presume de ello. U. en son de burla. 3. [...] El que se mete a hablar de materias en que es lego. 4. [...] Rústico avisado y diestro en el manejo de negocios superiores a su educación”.

Observamos que el bloque denotativo, a pesar de la aparente variedad, en principio alude a una persona que incurre en razonamientos sobre las cuestiones en las que es lega (cfr. la acepción 3 del DRAE). El componente de imagen de la locución ya revela una incongruencia interna, pues dos marcos cognitivos diferentes, el de "jurisprudencia” y el de "labores agrícolas", se ponen en comparación para formar una unidad denominativa. De esta forma, un abogado, que es un profesional en derecho institucionalmente formado, se identifica con un agricultor que, estereotípicamente, representa la ausencia de una instrucción académica previa, si no directamente la ignorancia y el analfabetismo. Tal incongruencia se resuelve humorísticamente a través del referente reflejado en el bloque denotativo.

Haciendo eco de los ejemplos anteriores, también en el caso de abogado de secano detectamos indicios de incongruencia en el bloque estilístico, pues en circunstancias neutras no es frecuente la coincidencia de registros propios de los dos marcos cognitivos recogidos en la locución.

En lo que respecta a los dos bloques evaluativos, también presentan ciertas particularidades que quisiéramos señalar. A primera vista, podría parecer que la evaluación racionalizada cualitativa se realiza en términos negativos, lo que corroboraría también la marca de despectivo que utiliza el DFDEA. No obstante, esa negatividad, si la hay, no presenta un grado alto de convencionalización, ya que no resulta aplicable, por ejemplo, a la totalidad de las acepciones recogidas en el DRAE (cfr. 4), así como muestra una elevada cancelabilidad en el segundo nivel del significado fraseológico. Lo podemos comprobar en el siguiente ejemplo, que proviene de la página web denominada http://www.abogadodesecano.es/ donde se hace la siguiente declaración de intenciones:

(7) Esta web pretende ser una herramienta de ayuda para el ciudadano de a pie, a la hora de afrontar diferentes trámites ante las administraciones e instituciones, así como una referencia para orientarse ante los diferentes problemas legales que surgen en el día a día.

Naturalmente, no resulta coherente pensar que los autores de la web se refieran a sí mismos en términos despectivos o que sean incompetentes para realizar la labor que anuncian. Es evidente, sin embargo, que se explota la semántica humorística de la UF - puesto que se parte de la incongruencia que la sustenta- con 
el fin de desarrollar una implicatura particularizada que, en este caso, se refiere a facilitar al ciudadano su relación con distintos órganos jurídicos y administrativos.

Por su parte, y consecuentemente con lo anterior, en el bloque de evaluación emotivo-emocional creemos que el sentimiento-actitud que prevalece se da justamente en términos del humor ${ }^{24} \mathrm{y}$ constituye el principal efecto perlocutivo buscado por esta UF. Por todas estas razones parece adecuado tratar abogado de secano como una UF humorística y marcarla como tal en el diccionario.

\subsection{Radio macuto}

Algunas locuciones susceptibles de considerarse humorísticas denotan su referente a través de una realidad inexistente. Así, la UF radio macuto, con el significado de "emisora imaginaria de donde parten rumores y bulos" (DFDEA), es marcada en el DUE como humorística, aunque no en otros diccionarios. Es confuso el origen de esta locución pero en la actualidad el hablante que la conoce es probable que la relacione con la imagen de noticias que se transmiten figuradamente de macuto (mochila, saco) en macuto, con lo cual pronto se convierten en meros rumores. De nuevo, por tanto, en el bloque motivacional encontramos las claves de la incongruencia, pues la incoherencia entre radio como medio de comunicación por excelencia que presupone rigor informativo y macuto como símbolo de una vida vagante y ciertamente caótica produce el efecto cómico. Si nos fijamos en otros bloques informativos, podemos destacar también que en lo que a la evaluación racionalizada se refiere, la locución tiende hacia el polo negativo, ya que hacer circular y aceptar como ciertas aquellas noticias que nos llegan por medio de rumores en principio está sancionado por la opinión pública. Todo esto provoca que en el bloque de evaluación emotivo-emocional el hablante que utiliza radio macuto pretende así marcar a su oyente la procedencia y las características de la información que le ofrece. La incongruencia queda resuelta en clave humorística al atender al referente de la UF que, como hemos visto al principio, indica una fuente de rumores e información frecuentemente falsa.

\subsection{Cuando las ranas críen pelo}

Un último ejemplo que quisiéramos mencionar se refiere a la locución cuando las

${ }^{24}$ En esta UF podemos ver que el efecto humorístico se sostiene especialmente en una de las seis fuentes de conocimiento que postula Attardo en su TGHV (Attardo y Raskin, 1991; Attardo, 1994: 222 y ss.), la de meta o blanco (target), que selecciona quién va a ser el objeto de la burla. A pesar de que se trata de una fuente opcional, en el caso de abogado de secano resulta sobresaliente debido al conocimiento estereotípico implicado en la formación de su significado. 
ranas crien pelo que significa "para dar a entender el tiempo remoto en que se ejecutará algo, o que se duda de la posibilidad de que suceda" (DRAE) o, sencillamente, "nunca" (DFDEA, DFEM). A pesar de que esta UF no está marcada como humorística en ninguna de las fuentes consultadas, es interesante observar cómo lo absurdo de la imagen subyacente (i. e. bloque motivacional) conforma la fase de incongruencia cuya resolución se presenta en términos humorísticos en el bloque denotativo (i. e. "nunca”), concatenada, además, a una valoración racionalizada en términos cuantitativos, ya que se eleva el grado de lo remoto o lo imposible de algo.

Además, en el caso de esta locución hay otro aspecto que nos gustaría señalar especialmente y que no se daba en los ejemplos anteriores. Formalmente, la locución cuando las ranas crien pelo se compone de una estructura temporal que, en principio, debería indicar algún punto en el futuro. No obstante, el significado de la UF desmantela esta suposición. Todo ello, nos hace ver que también el bloque gramatical participa de la generación de informaciones semánticas y puede verse implicado en los procesos de incongruencia-resolución que fundamentan una interpretación humorística de la UF.

\section{CONCLUSIONES}

Las reflexiones que hemos ido desarrollando a lo largo de este trabajo nos llevan a plantear conclusiones que, aun siendo provisionales, permiten ver una serie de líneas por las que pudieran discurrir las investigaciones futuras.

En primer lugar, hemos visto que el tratamiento que se da a las unidades fraseológicas en los diversos diccionarios, tanto fraseológicos como generales y de uso, no consigue reflejar toda la riqueza de informaciones de diversa índole que engloba el significado de una UF, ni tampoco las particularidades de su comportamiento lingüístico. Por ello, se afirma como acuciante la necesidad de reformular las pautas de la descripción lexicográfica del significado de UF, pues el criterio funcional, y no el formal, ha de convertirse en el punto de partida de tal descripción.

Si atendemos a la función de las UF, comprobamos que ésta no difiere en absoluto de la de cualquier lexema libre y consiste en denominar las distintas realidades, sentimientos, acciones, etc. Ahora bien, tal denominación es cualitativamente distinta, ya que parte del carácter polilexemático y, por ende, polisemántico de las UF, por lo que una indagación previa sobre las particularidades de la significación fraseológica se hace imprescindible.

El modelo de significación fraseológica en dos niveles, que hemos expuesto brevemente en el apartado 3, pone de manifiesto la importancia de muchos aspectos que a menudo quedan fuera de la descripción lexicográfica. El modelo macrocomponencial adaptado de Telia $(1990,1996)$ que articula el significado fraseológico de primer nivel provee, a nuestro juicio, unas bases lo suficientemente 
explícitas para una descripción y fijación adecuadas de la semántica de una UF en el diccionario. En este sentido destacamos, por ejemplo, la importancia de reflejar las informaciones evaluativas que actúan como implicaturas de distinto grado de convencionalización en el primer nivel del significado fraseológico. El humor es una de tales características implicaturales que, en los casos en los que es resultado de la intrusión de factores pragmáticos en la semántica de la UF (Levinson, 2004), ha de marcarse en el diccionario en tanto que información constituyente del primer nivel del significado fraseológico.

Atendiendo a que el humor lingüístico es concebido por la mayoría de los estudiosos del tema en relación al modelo psicológico de incongruencia-resolución, cabe plantearse que una UF humorística puede sancionarse como tal en el diccionario si detectamos en su semántica indicios y rastros de una posible situación original de choque de marcos cognitivos seguida de una resolución en clave humorística. De esta manera, la aplicación a estos casos del modelo de significado fraseológico que hemos presentado permite diseñar unos criterios claros sobre la inclusión o no de la marca correspondiente en la descripción lexicográfica. El sucinto análisis de las UF concretas que hemos realizado en este trabajo muestra la validez de las afirmaciones vertidas. Así, hemos podido comprobar que mientras que unas UF sancionadas como humorísticas en algunos diccionarios no cumplen las condiciones propuestas (v. g. para el arrastre), otras sí responden a las pautas desarrolladas a pesar de no tener reflejada tal circunstancia en su descripción lexicográfica (v. g. vida y milagros, cuando las ranas crien pelo, etc.). Desde nuestra perspectiva, los criterios que han de guiar la inclusión de la marca "humorístico" diseñados resultan lo suficientemente explícitos y permiten acabar con la tradicional vaguedad que caracteriza este aspecto.

Cabe señalar, asimismo, que el estudio realizado ha abierto para nosotros nuevos interrogantes que esperamos abordar en los trabajos futuros. Por ejemplo, hemos constatado que la incongruencia que sustenta el carácter humorístico de una UF puede darse tanto entre los diferentes bloques informativos como en el interior de uno solo. Así, el componente de imagen o el bloque estilístico pueden encerrar una incoherencia interna que propiciaría una consideración humorística y cuyo estudio podría tener interesantes aplicaciones para la enseñanza de la fraseología y el humor lingüístico a extranjeros.

En definitiva, el caso de las UF humorísticas es solo una muestra de la insuficiencia de los criterios lexicográficos tradicionales para una adecuada representación del significado fraseológico. Asimismo, la reciente realidad de las nuevas tecnologías de la información y su aplicación a los diversos ámbitos lingüísticos demanda nuevos enfoques que permitan diseñar modelos articulados que sean operativos para el tratamiento electrónico de distintas manifestaciones del lenguaje. El estudio que hemos presentado puede servir, en nuestra opinión, como punto de partida para el caso de las UF. 


\section{REFERENCIAS}

Alcaraz Varó, E. (1990). Tres paradigmas de la investigación lingüistica. Alcoi: Marfil.

Attardo, S. (1994). Linguistic theories of humor. Berlin: Mouton de Gruyter.

Attardo, S. (2001a). Humorous texts: A semantic and pragmatic analysis. Berlin: Mouton de Gruyter.

Attardo, S. (2001b). Humor and irony in interaction: From mode adoption to failure of detection. En Anolli, L., Ciceri, R. y G. Riva (eds.), Say not to Say: New perspectives on miscommunication (pp. 166-185). Amsterdam: IOS Press.

Attardo, S. y V. Raskin. (1991). Script Theory Revis(it)ed: Joke similarity and joke representation model. International Journal of Humor Research, 4 (3/4), $347-411$.

Bally, Ch. (1951). Traité de Stylistique française. Paris: Librairie C. Kincksiek.

Baranov, A. y D. Dobrovol'skij. (1996). Idiomatichnost' i idiomy. Voprosy jazykoznanija, 5, 51-64.

Baranov, A. y D. Dobrovol'skij. (2000). Rechevyje formuly v dialogue. Trudy Mezhdunarodnogo seminara Dialog-2000. Disponible en http://www.dia$\log -21 . r u /$ materials/archive.asp? $\mathrm{id}=6250 \& \mathrm{y}=2000 \&$ vol=6077\#_ftnref1.

Carneado, Z. y A. Ma . Tristá. (1983). Estudios de fraseología. La Habana: ACC. Casares, J. (1950). Introducción a la lexicografia moderna. Madrid: CSIC.

Cifuentes, J.L. (1994). Gramática cognitiva. Fundamentos críticos. Madrid: Eudema.

Cifuentes, J.L. (2003). Locuciones prepositivas: sobre la gramaticalización preposicional en español. Alicante: Universidad de Alicante.

Corpas Pastor, G. (1996). Manual de fraseología española. Madrid: Gredos.

Cuenca, M. J. y J. Hilferty. (1999). Introducción a la lingüistica cognitiva. Barcelona: Ariel.

Dobrovol'skij, D. (1990). Tipologuija idiom. En Telia (ed.), Frazeografija v Masinnom fonde russkogo jazyka (pp. 48-67). Moskva: Nauka.

Dobrovol'skij, D. y E. Piirainen. (2005). Figurative language: Cross-cultural and cross-linguistic perspectives. Amsterdam: Elsevier.

Doval, G. (1995). Del hecho al dicho. Madrid: Ediciones del Prado.

Feyaerts, K. (2006). Toward a dynamic account of phraseological meaning: Creative variation in headlines and conversational humour. IJES, 6 (1), 57-84.

Gutiérrez Cuadrado, J. (dir.). (1996). Salamanca: Diccionario Salamanca de la Lengua Española. Salamanca-Madrid: Universidad de Salamanca-Santillana.

Latta, R. (1998). The basic humor process: A Cognitive-shift theory and the case against incongruity. Berlin: Mouton de Gruyter

Levinson, S. (2004). Significados presumibles: La teoría de la implicatura conversacional generalizada. Madrid: Gredos. 
Martínez Marín, J. (1996). Estudios de fraseología española. Málaga: Ágora.

Meix, F. (1982). La dialéctica del significado lingüistico. Salamanca: Universidad.

Moliner, M. (1998). DUE: Diccionario de uso del español. Madrid: Gredos.

Norrick, N.R. (1993). Conversational joking: Humor in everyday talk. Bloomington: IUPress.

Penadés Martínez, I. (2002). Diccionario de locuciones verbales para la enseñanza del español. Madrid: Arco Libros.

Penadés Martínez, I. (2005). Diccionario de locuciones adverbiales para la enseñanza del español. Madrid: Arco Libros.

Penadés Martínez, I. (2008). Diccionario de locuciones nominales, adjetivas y pronominales para enseñanza del español. Madrid: Arco Libros.

Raskin, V. (1985). Semantic mechanisms of humor. Dordrecht: Reidel.

RAE. (2001). DRAE. Diccionario de la lengua española (22a ed.). Madrid: Espasa.

Robles, F. (2007). Fuentes para el estudio del tratamiento de la fraseología en la lexicografía española monolingüe y bilingüe. Disponible en http://www.linred. es/informacion_pdf/informacion15_04072007.pdf.

Ross, A. (1998). The language of humour. London: Routledge.

Ruiz Gurillo, L. (1997). Aspectos de fraseología teórica española. València: Universitat.

Ruiz Gurillo, L. (2012). La lingüistica del humor en español. Madrid: Arco Libros.

Ruiz Gurillo, L., C. Marimón, X. A. Padilla y L. Timofeeva. (2004). El Proyecto GRIALE para la ironía en español: Conceptos previos. ELUA, 18, 231-242.

Santamaría, I. (2011). Entre la Pragmática y la Lexicografía: la marca humorístico en los diccionarios monolingües de aprendizaje del español. Revista de Lexicografía, 17, 179-208.

Seco, M., Andrés, O. y G. Ramos. (2004). DFDEA: Diccionario fraseológico documentado del español actual. Madrid: Aguilar.

Suls, J. M. (1972). A two-stage model for the appreciation of jokes and cartoons. In J. H. Goldstein y P. E. McGhee (eds.), The psychology of humor (pp. 81100). New York: Academic Press.

Telia V. (ed.) (1990). Frazeografija v Masinnom fonde russkogo jazyka. Moskva: Nauka.

Telia, V. (1996). Russkaja fraseologija. Moskva: Shkola "Yazyki russkoj kultury".

Timofeeva, L. (2009a). Las unidades fraseológicas. En Ruiz Gurillo L. y X. Padilla (eds.), Dime cómo ironizas y te diré quién eres: Una aproximación pragmática a la ironia (pp. 193-217). Frankfurt am M.: Peter Lang.

Timofeeva, L. (2009b). La desautomatización fraseológica: un recurso para crear y divertir. En Jiménez Ruiz, J. L. y L. Timofeeva (eds.), Estudios de Lingüistica: Investigaciones lingüisticas en el siglo XXI (pp. 249-271). Alicante: Universidad de Alicante. 
Timofeeva, L. (2012). El significado fraseológico. En torno a un modelo explicativo y aplicado. Madrid: Ediciones Liceus.

Torres Sánchez, Ma A. (1999). Estudio pragmático del humor verbal. Cádiz: Universidad de Cádiz.

Varela F. y H. Kubarth. (1994). DFEM: Diccionario fraseológico del español moderno. Madrid: Gredos.

Utsumi, A. (2000). Verbal irony as implicit display of ironic environment: Distinguishing ironic utterances from nonirony. Journal of Pragmatics, 32, 1777 1806.

Vinogradov, V. (1977). Izbrannyje trudy. Leksikologuija y leksikografia. Moskva: Nauka.

VV.AA. (1995). Alcalá: Diccionario para la enseñanza de la lengua española. Alcalá de Henares: Universidad de Alcalá de Henares-VOX.

Wotjak, G. (1983). En torno a la traducción de unidades fraseológicas (con ejemplos tomados del español y el alemán). Linguistische Arbeitsberichte, 40, 56-80.

Zuluaga, A. (1980). Introducción al estudio de las expresiones fijas. Frankfurt: Peter Lang. 